\title{
The Realization of Population Zero
}

\author{
Qian Yang \\ School of North China Electric Power University, Baoding 071000, China \\ 1026833458@qq.com
}

\begin{abstract}
This study is about setting a policy model including the factors of income, education and equality to result in a set of policy recommendations which would be implemented to the Population Zero. The mission of Population Zero is to create a sustainable society by maximizing both economic output and happiness in the work place for its citizens. Our policy recommendations contain these aspects: influence factors of GDP and happiness.[1] We established a Linear programming model so as to find the best result of the double guided balance. Firstly, we set the GDP Regression function including the factors of income, the labor force population invested in GDP growth, the temporal welfare of the population, the individual characteristics of the labor force, the education-related infrastructure invested in GDP growth and the total amount of current assets used to raise the skill level of the population. At the same time, we set the happiness Regression function including the factors of GDP, Gini coefficient, social welfare, income, individual characteristic. And we use the Z-score method to normalize the data, the dual objective function criterion is transformed into a single objective function, so the objective function of GDP and happiness double objective equilibrium could be established next, and define it as GDP-Happiness Mission index. We can use this index to reflect the degree of completion of Population Zero.
\end{abstract}

Keywords: Population Zero, GDP, happiness, Z-score method.

\section{Introduction}

The issue of Population Zero's mission is maximizing both economic output (GDP) and happiness. We need to construct an economic-labor-education system that matches Population Zero. The most suitable economic-labor-education system makes the GDP and happiness both optimal. Based on the above two points, we construct the correlation function of GDP and happiness respectively, and then standardize the two to make the double objective optimization problem into a single-objective optimization problem. Due to the impact of GDP and happiness variables are very complicated, in order to simplify the problem research, we first select the economic, labor, education-related parameters, and other variables are assumed to be constants not reflected in the initial construction of the first objective function expression to more focused on the economic - labor - the construction of the education system. 


\section{The Function of GDP}

$G D P=f((L, E, L S), F I, T I, T W$, Income $)$

Since we need to construct an economic-labor-education system in the end, the relevant parameters in the economic system for the GDP target are Income (the gross income of the inhabitants), and the labor system variables are $\mathrm{L}$ (the labor force population invested in GDP growth), TW (the temporal welfare of the population) and LS (the individual characteristics of the labor force, the main factors are gender, income and so on).[2] The variables that are involved in the education system are $\mathrm{E}$ (the education level of labor force population invested in GDP growth), FI (the education-related infrastructure invested in GDP growth) and TI (the total amount of current assets used to raise the skill level of the population).

\section{The Function of Happiness}

$$
\begin{aligned}
& \text { Happiness }=\beta_{1} X_{1}+\beta_{2} X_{2}+\beta_{3} X_{3}+\beta_{4} X_{4}+\varepsilon \\
& X_{2}=f\left(\frac{G D P}{P}, \text { Ginicoefficient }, T_{\text {social welfare }}\right) \\
& X_{3}=f(A I, R I) \\
& X_{4}=f(\text { sex, age }, E L,(M S, M E))
\end{aligned}
$$

For the happiness goal, the relevant parameters in the economic system are X2 (describe the macroscopic variables of macroeconomic development), and the parameters related to X2 are GDP per capita, Gini coefficient, social welfare level and so on. There is also a parameter is X3 (income variable), with the relevant parameters of absolute income and relative income, the introduction of the relative income variable is built on the psychology of people have to compete under the premise of happiness. The variables involved in the labor force system are X4 (individual characteristics), which include gender, age, educational level, marital status, employment status statistics based on marital status and other influencing factors.

\section{Transformation of the Functions}

We use the Z-Score method to normalize the index data

$$
X_{i j}(\mathrm{i}=1,2 ; \mathrm{j}=1,2), Z_{i j}=\left(X_{i j}-\bar{X}_{j}\right) / \delta_{i j} .
$$


Which, $\quad \bar{X}_{j}=\frac{1}{p} \sum_{i=1}^{p} X_{i j}, \quad \delta_{\mathrm{j}}=\sqrt{\frac{1}{p} \sum_{i=1}^{p}\left(X_{i j}-\bar{X}_{j}\right)^{2}}$. The normalized matrices of the obtained data indicators are, $Z^{0}=\left[\begin{array}{cc}Z^{0} & Z_{12}^{0} \\ Z_{21}^{0} & Z_{22}^{0}\end{array}\right]$.

Construct the correlation coefficient matrix of the index data R: $\mathrm{r}_{\mathrm{ij}}=\frac{1}{\mathrm{p}-1} \sum_{\mathrm{s}=1}^{\mathrm{p}} \mathrm{Z}_{\mathrm{ij}}^{\mathrm{o}} \mathrm{Z}_{\mathrm{kj}}^{\mathrm{o}}(\mathrm{i}, \mathrm{k}=1,2)$.

Next, to solve the characteristic equation $|\lambda I \bullet R|=0$.

And obtain its non-negative characteristic roots $\lambda_{\mathrm{i}}(\mathrm{i}=1,2, \cdots, \mathrm{m})$, and eigenvectors $\mathrm{y}=\left(\mathrm{y}_{1}, \mathrm{y}_{2}, \cdots, \mathrm{y}_{m}\right)$.

Next, the variance contribution ratio of each component is calculated by calculating $\lambda_{i}$, $\mathrm{p}_{\mathrm{i}}=\lambda_{\mathrm{i}} / \sum_{\mathrm{i}=1}^{\mathrm{n}} \lambda_{\mathrm{i}}(\mathrm{i}=1,2)$ where $\mathrm{m}<2$ is the smallest positive integer satisfying $\sum_{\mathrm{i}=1}^{\mathrm{m}} \lambda_{\mathrm{i}} / \sum_{\mathrm{i}=1}^{\mathrm{n}} \lambda_{\mathrm{i}} \geq \mathrm{e}$ (Generally take $\left.\mathrm{e}=0.85\right)$.[3] The above-mentioned $\mathrm{n}=2$. The main component of the data index of this subsystem is $y=\left(y_{1}, \cdots, y_{m}\right)$, the calculation of happiness and GDP's integrated mission completion index Mission $=\sum_{i=1}^{m} p_{i} \bullet y_{i}$. Finally, We construct a mission-complete level objective model for a double objective integration model that needs to be achieved is max Mission $=\sum_{i=1}^{m} p_{i} \bullet y_{i} \cdot$

\section{Conclusion}

By converting the functions, we can standardize the GDP and Happiness to transform the double objective optimization problem into a single-objective optimization problem. Therefore, we can use this unique standard to evaluate the completion of Population Zero. 


\section{Acknowledgments}

This work was finish under the direction of my tutor, Ms.Liu. She helped me a lot in the grammar of the article. At the same time, thanks to the documents provided by CNKI and Google.

\section{References}

[1] MAURIZIO P. Scitovsky and the Income - Happiness Paradox [J ] . The Journal of Socio-Economics, 2013, 4 (43): 1-10.

[2] Jin Tao, Shao Hongwei. The Analysis of the Optimal Income Distribution System-An Inspiration from the Inversed-U Effect of Income Distribution on Economic Growth [J]. Research on Quantitative, Technical, and Economic, 2016, (05):44-64.

[3] Xiaowei Ma, Changjie Chen, Yiming Wei , Xiaofeng Fu, China's sustainable development model based on multi-objective programming optimization research[J]. Chinese Journal of Management Science, 2004. 